\title{
ISOLATION OF SALMONELLA FROM SEWAGE BY ANAEROBIC METHODS
}

\author{
W. J. RYAN \\ Public Health Laboratory, Exeter, EX2 5AD
}

THE combination of enrichment in selenite $F$ broth with plating on deoxycholate citrate agar has proved very successful for the isolation of salmonellae from faeces and is a method in widespread use. The same combination is relatively inefficient when sewage is examined instead of faeces. This seems to be largely due to a difference in the bacterial flora of faeces and sewage, the latter often containing large numbers of Proteus and Pseudomonas organisms that may not be inhibited by the usual selenite broth-deoxycholate citrate agar technique.

It seemed likely that, in making cultures from sewage, the growth of pseudomonads could be eliminated merely by incubating the cultures under anaerobic conditions. Preliminary trials confirmed that this was indeed the case; and it was found in addition that salmonellae growing under these conditions produced distinctive jet-black colonies that were easily identifiable. These results prompted an examination of anaerobic methods in the routine examination of sewage for salmonellae.

\section{MATERIALS AND METHODS}

Salmonella strains. All salmonellae used in experimental work were isolated from specimens examined in this laboratory. Most of them were recent isolates.

Media. The deoxycholate citrate agar (DCA) used was a laboratory version of Hynes' modification of Leifson's medium. As the exact composition may be important, the formula is given in appendix A. The selenite enrichment broth was a laboratory version of selenite $F$ medium and the formula is also given in appendix $\mathrm{A}$. The brilliant green medium was Bacto Brilliant Green Agar (Difco).

Anaerobic methods. For anaerobic incubation of plates, McIntosh and Fildes jars equipped with cold catalysts were used. The jars were evacuated, and hydrogen and approximately 10 per cent. $(\mathrm{v} / \mathrm{v})$ carbon dioxide admitted from gas cylinders. For anaerobic selenite cultures the medium was put into $\frac{3}{4}-\mathrm{in}$. $(20-\mathrm{mm})$ diameter tubes in $20-\mathrm{ml}$ volumes, boiled for $5 \mathrm{~min}$., cooled, inoculated, and then sealed with a $5-\mathrm{mm}$ layer of sterile liquid paraffin.

Sewage samples. Sewage was sampled by means of sewer swabs (Moore, 1948). Most of the specimens were from the drainage system of a local abattoir.

Sewage examination. The method in routine use was to flood the sewer swab with selenite $\mathrm{F}$ medium, incubate at $43^{\circ} \mathrm{C}$ and next day make six ten-fold dilutions of the enrichment cultures in quarter-strength Ringer's solution. Brilliant green agar plates were then inoculated with $0.1 \mathrm{ml}$ of each dilution, incubated at $37^{\circ} \mathrm{C}$ and examined at 24 and $48 \mathrm{hr}$ for salmonellalike colonies; these were picked for identification. For anaerobic cultures the same dilutions were similarly inoculated on deoxycholate citrate agar plates which were incubated at $37^{\circ} \mathrm{C}$ in anaerobic jars in an atmosphere of hydrogen and carbon dioxide; jet-black salmonella-like

Received 18 May 1972; accepted 2 June 1972.

J. MED. MICROBIOL.-VOL. 5 (1972) 
colonies were sought after 24 and $48 \mathrm{hr}$. When examining for Salmonella typhi, selenite cultures were incubated at $37^{\circ} \mathrm{C}$ instead of $43^{\circ} \mathrm{C}$.

\section{RESULTS}

Salmonella colonies on anaerobic deoxycholate citrate agar

Salmonella colonies on anaerobically incubated DCA plates were very distinctive. They were quite small after 24 hours' incubation but after $48 \mathrm{hr}$ they were usually about $2 \mathrm{~mm}$ in diameter. They were jet-black and opaque with sometimes a narrow colourless rim. The surface was smooth and shining or slightly granular. The colonies emulsified easily and gave satisfactory slide agglutination. Brownish translucent colonies were not salmonellae. To date, the only bacteria found to produce colonies that might be confused with salmonella colonies were members of the Citrobacter group or Enterobacter cloacae. These colonies, however, were usually more slow-growing, rarely appeared before the 3rd or 4th day, often had a greyish centre, and were sometimes tough and adherent to the medium.

\section{The importance of sodium thiosulphate}

Hynes' modification of Leifson's deoxycholate citrate agar contains sodium thiosulphate. This was found to be an essential ingredient for blackening of salmonella colonies under anaerobic conditions. When thiosulphate was omitted, or when a medium prepared from a formula that does not include thiosulphate was used, no blackening occurred. The final concentration of sodium thiosulphate in the medium in routine use was 0.85 per cent. (w/v). Increasing the concentration to 1.2 per cent. (w/v) appeared to intensify the blackening and had no deleterious effect on the growth of salmonellae, nor was the selectivity of the medium impaired.

\section{Salmonellae tested on anaerobic deoxycholate citrate agar}

Pure cultures of the following salmonellae gave typical jet-black colonies when grown anaerobically on DCA plates; figures in brackets indicate the number of strains tested: $S$. abony (1), S. agona (3), S. anatum (2), S. bredeney (1), S. derby (1), S. dublin (6), S. enteritidis (2), S. haardt (1), S. indiana (2), $S$. livingstone (2), S. muenchen (1), S. newport (2), S. paratyphi B (2), S. saintpaul (1), S. stanley (1), S. tennessee (1), S. typhi (3), S. typhimurium (9), S. 4,12:d (1), $S$. unidentified (1). Six further strains, one of Salmonella infantis and five of $S$. typhimurium, at first were thought to be negative in respect of anaerobic blackening of colonies. It was found, however, that some blackening occurred if incubation was prolonged for 3-4 days. This could be greatly intensified and the incubation period shortened to 2-3 days if, after overnight anaerobic growth, the plates were left exposed to air at room temperature (about $20^{\circ} \mathrm{C}$ ) for 2-3 hr before replacing in the jar for further anaerobic incubation. Increasing the thiosulphate concentration of the medium to $1 \cdot 2$ per cent. $(\mathrm{w} / \mathrm{v})$ also enhanced the blackening. These weak reactions were not shown to be associated with any particular phage type of $S$. typhimurium; weak reacters 
included members of phage-types 1a, 1a var. 2, U20 and U165, while strong reacters included members of types 1a, 4, U129, U204 and U71. Both weakly reacting and strongly reacting strains were associated with acute diarrhoea in man.

All salmonellae tested belonged to subgenus 1 . The behaviour of members of other subgenera is at present unknown.

\section{The effect of carbon dioxide}

The addition of carbon dioxide to the anaerobic jar was not necessary for adequate blackening of salmonella colonies to occur. However, if hydrogen alone was added it was found that colonies of Proteus might develop and produce a diffuse blackening of the medium which made results difficult to read. This growth could be controlled by the addition of approximately 10 per cent. (v/v) carbon dioxide. Although not completely inhibited, colonies of Proteus were prevented from attaining more than pin-point size over the incubation times used and trouble from this source was eliminated. Growth of pseudomonads was inhibited in either case.

\section{Isolation of salmonellae from sewage}

Ten sewer swabs were examined in parallel by the routine method, with subculture on to brilliant green agar, and by the anaerobic method, with subculture on to DCA. Salmonellae were isolated from seven swabs by the routine technique and from nine by the anaerobic method. In no case was a specimen positive on brilliant green agar and negative on anaerobic DCA.

Plates were examined at 24 and $48 \mathrm{hr}$. Growth was more rapid on the brilliant green plates and colonies were larger. Salmonella colonies were usually found on both plates at $24 \mathrm{hr}$ but, on the anaerobic plates, they were much more obvious and numerous at $48 \mathrm{hr}$; the colonies were easily recognisable. In this series, incubation of the anaerobic plates for more than $48 \mathrm{hr}$ did not give any increase in salmonella isolation, but, in view of the known existence of slow reacters, it is advisable to continue incubation for 3 days. The appearance of colonies of Citrobacter on prolonged incubation may lead to some difficulty.

The salmonellae isolated from these specimens were: S. anatum, S. dublin, $S$. enteritidis and S. typhimurium. Some of the swabs were also examined in parallel on aerobic DCA plates but this was discontinued because salmonellae could not be isolated from any of them.

\section{Isolation of Salmonella typhi}

S. typhi presented special problems, probably because of its slow growth compared with that of other enterobacteria. The three strains tested did indeed produce typical black colonies anaerobically on DCA but about 3 days' incubation was required for optimal development. S. typhi was readily grown from small inocula (about five viable organisms) introduced into $10 \mathrm{ml}$ of selenite $\mathrm{F}$ broth and incubated for $24 \mathrm{hr}$ at $37^{\circ} \mathrm{C}$ before plating out anaerobically, provided 
the anaerobic cultures were prolonged for 3 days. However, if 1-2 $\mathrm{ml}$ of raw sewage was also introduced into the selenite $\mathrm{F}$ broth, the recovery of $S$. typhi by this method became very difficult and usually failed. This remained so even when the inoculum of $S$. typhi was increased to several hundred viable organisms. Diffusion experiments with sewage in Heatley cups on a lawn of $S$. typhi failed to show any inhibitory effect of the sewage itself, and a sample of the sewage flora did not show any colicine activity against the $S$. typhi strains. It seemed possible that fermentation of lactose by the more rapidly developing coliform colonies lowered the $p \mathrm{H}$ of the medium sufficiently to inhibit the growth of $S$. typhi. The omission of lactose from the DCA showed this to be so; $S$. typhi could now be recovered readily from small inocula even in the presence of sewage. The presence of lactose in the medium was not necessary for colony identification, which depended on the characteristic black appearance.

A further difficulty was presented by the presence of other salmonellae in sewage. These, when present, developed much more quickly than $S$. typhi and so completely outgrew the latter that it was almost impossible to detect. Harvey and Price (1964) showed the value of double-strength selenite F broth in the isolation of $S$. typhi from sewage-polluted water. They demonstrated that good growth from minimal inocula of $S$. typhi occurred in this medium in $24 \mathrm{hr}$ whereas other salmonellae were largely suppressed. This finding was confirmed. When double-strength selenite medium was substituted for the usual selenite $F$ broth and appropriate dilutions were subcultured after $24 \mathrm{hr}$ at $37^{\circ} \mathrm{C}$ on to lactose-free DCA which was incubated anaerobically, S. typhi was readily recovered from small inocula (five to ten viable organisms) even in the presence of sewage that contained large numbers of other salmonellae. The other salmonellae were apparently completely suppressed by the doublestrength selenite technique; when ordinary selenite $\mathrm{F}$ broth was used in parallel, these salmonellae appeared in large numbers and prevented the isolation of S. typhi.

Thus enrichment in double-strength selenite $\mathrm{F}$ broth for $24 \mathrm{hr}$ at $37^{\circ} \mathrm{C}$ followed by plating on to lactose-free DCA which was incubated anaerobically for 2-3 days allowed the ready isolation of $S$. typhi from sewage artificially contaminated with small numbers of that organism. Naturally infected sewage was not available.

None of the strains of S. typhi showed any growth on Wilson and Blair's bismuth sulphite agar under anaerobic conditions although good growth occurred aerobically. A commercial preparation was used.

Anaerobic growth on DCA did not affect the Vi-agglutinability of S. typhi. The phage types of the strains used were: type $\mathrm{A}$ (two strains) and type $\mathrm{Cl}$ (one strain).

\section{Anaerobic cultures in selenite medium}

All salmonellae including $S$. typhi gave good growth from small inocula in $24 \mathrm{hr}$ in selenite F medium sealed with liquid paraffin. S. typhi gave similar growth in double-strength selenite $F$ broth with a paraffin seal. There seemed 
to be little or no advantage, however, in using anaerobic selenite cultures when examining sewage; sealed and unsealed cultures gave similar results. This may be partly due to the fact that aerobic selenite cultures were always sampled from the depths of the medium to avoid highly aerobic organisms that might be concentrated near the surface.

\section{DisCUSSION}

The blackening of salmonella colonies that occurs on DCA plates incubated anaerobically is probably due to reduction of thiosulphate to sulphide. The ability to utilise sulphur compounds anaerobically may be favourable to the growth of salmonellae in the anaerobic environment of the gut. It was observed with one old stock strain of $S$. typhimurium, which produced a mixture of black and colourless colonies, that the black colonies grew more rapidly and were much larger than the colourless ones. The importance of sulphur metabolism in enrichment media has been pointed out, for tetrathionate broth by Pollock, Knox and Gell (1942), and for selenite broth by Smith (1959).

The present limited study suggests that anaerobic methods may have a place in the isolation of salmonellae from heavily contaminated material. For most salmonellae, media already in use may be employed anaerobically but for the isolation of $S$. typhi slight modifications are necessary. Although all salmonella strains tested in the present survey gave black colonies on anaerobic DCA plates this may quite possibly not always be so. When, however, sewage is being examined for a salmonella known to be positive in this respect, the procedures suggested here might well replace standard methods.

\section{SUMMARY}

Salmonellae present in or artificially inoculated into sewage were readily isolated by plating selenite $\mathrm{F}$ enrichment cultures on deoxycholate citrate agar provided the plates were incubated anaerobically in the presence of about 10 per cent. (v/v) carbon dioxide. Under these conditions, salmonellae gave distinctive jet-black colonies, pseudomonads were suppressed and the growth of Proteus was markedly inhibited. A modified procedure was required for satisfactory recovery of Salmonella typhi, notably the use of double-strength selenite medium and the omission of lactose from the deoxycholate citrate agar.

Appendix A: Preparation of media

Base

1. Deoxycholate citrate agar (adapted from Cruickshank, 1965)

(a) Peptone, Oxoid L37 Powdered Lab Lemco Distilled water

(b) Agar Distilled water

(c) Neutral red Distilled water

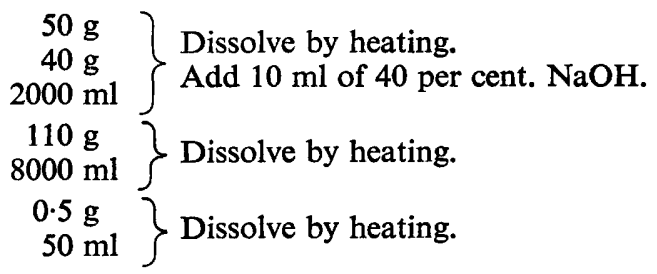

Mix $(a),(b)$ and (c) together. Adjust $p \mathrm{H}$ to $8 \cdot 2-8 \cdot 4$ if necessary. Dispense in 200-ml amounts. Autoclave. 
Solution A

Sodium citrate Sodium thiosulphate

Ferric citrate scales

Distilled water

$\left.\begin{array}{r}340 \mathrm{~g} \\ 340 \mathrm{~g} \\ 40 \mathrm{~g} \\ 2000 \mathrm{ml}\end{array}\right\} \begin{aligned} & \text { Dissolve by heating. } \\ & \text { Dispense in 200-ml amounts. } \\ & \text { Steam } 30 \mathrm{~min} .\end{aligned}$

Solution B

Sodium deoxycholate

Distilled water

$200 \mathrm{~g}\}$ Dissolve by heating. Dispense in $200-\mathrm{ml}$ $2000 \mathrm{ml}\}$ amounts. Steam $30 \mathrm{~min}$.

Lactose solution

Lactose

Distilled water

$200 \mathrm{~g}$ Dissolve. Dispense in 100-ml amounts. Steam $1000 \mathrm{ml}\} 30 \mathrm{~min}$.

Final medium

Melt $200 \mathrm{ml}$ of the base, cool to $50^{\circ} \mathrm{C}$, and add $10 \mathrm{ml}$ of solutions A, B and lactose. Pour plates. Final $p \mathrm{H}$ is about $\mathbf{7 \cdot 3}$.

\section{Modified deoxycholate citrate agar}

As above, but the lactose solution is omitted and instead $5 \mathrm{ml}$ of 15 per cent. (w/v) sodium thiosulphate solution, previously sterilised by steaming $30 \mathrm{~min}$., are added.

3. Selenite F broth (adapted from Hobbs and Allison, 1945)

Sodium hydrogen selenite Sodium phosphate anhydrous $\left(\mathrm{Na}_{2} \mathrm{HPO}_{4}\right)$ Mannitol

Peptone, Oxoid L37

Distilled water

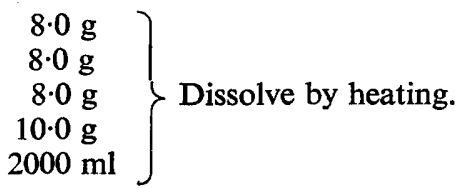

If necessary, adjust $p \mathrm{H}$ to 7.5 by adding N.HCl. Dispense in $200-\mathrm{ml}$ amounts or in tubes of $10 \mathrm{ml}$. Steam $30 \mathrm{~min}$.

\section{Double-strength selenite $F$ broth}

As above, but only $1000 \mathrm{ml}$ of distilled water is used.

\section{APPENDIX B: SEWAGE EXAMINATION}

\section{For salmonellae in general}

About $10 \mathrm{ml}$ of sewage or of fluid expressed from a sewer swab are placed in a large test tube $(180 \times 25 \mathrm{~mm})$ and $50-80 \mathrm{ml}$ selenite $F$ broth is added. After 24 hours' incubation in a waterbath at $43^{\circ} \mathrm{C}, 1 \mathrm{ml}$ of culture is removed by pipette from the depths of the medium and added to $9 \mathrm{ml}$ of quarter-strength Ringer's solution, giving a 1 in 10 dilution. Further dilutions of 1 in 100 and 1 in 1000 are similarly prepared; it is rarely necessary to make higher dilutions. The surface of a deoxycholate citrate agar plate is seeded with $0.1 \mathrm{ml}$ of each dilution by means of a spreader. After drying at room temperature, the plates are placed in an anaerobic jar equipped with a cold catalyst. The jar is evacuated and hydrogen with approximately 10 per cent. $(\mathrm{v} / \mathrm{v})$ carbon dioxide admitted. After overnight incubation at $37^{\circ} \mathrm{C}$, the jar is opened and the plates are examined for suspicious colonies; these are picked to MacConkey agar plates for investigation. The plates are left exposed to the air at room temperature for $2-3 \mathrm{hr}$, then returned to the jar for further anaerobic incubation. They are inspected again on the 2 nd day and finally, if necessary, on the 3rd day. 
If a sewer swab is received in a wide-mouthed bottle (e.g., a 200-ml " honey " jar), instead of transferring expressed fluid to a large test-tube, selenite $F$ broth may be added directly to the jar so as to reach the shoulder.

\section{For Salmonella typhi}

The procedure is as above with the following modifications: (a) double-strength selenite $\mathrm{F}$ broth is used; (b) selenite cultures are incubated at $37^{\circ} \mathrm{C} ;(c)$ modified deoxycholate citrate agar without lactose and with increased thiosulphate is used; this may also be used for all other salmonellae; $(d)$ plates are incubated for at least 3 days.

\section{REFERENCES}

Cruickshank, R. 1965. Medical microbiology, 11th ed. Edinburgh and London, p. 760.

HaRvey, R. W. S., AND PRICE, T. H. 1964. The isolation of Salmonella typhi from selenite enrichment media. Mon. Bull. Minist. Hlth, 23, 233.

HobBs, BetTy C., AND Allison, V. D. 1945. Studies on the isolation of Bact. typhosum and Bact. paratyphosum B. Mon. Bull. Minist. Hlth, 4, 63.

MOORE, B. 1948. The detection of paratyphoid carriers in towns by means of sewage examination. Mon. Bull. Minist. Hlth, 7, 241.

Pollock, M. R., KNox, R., AND Gell, P. G. H. 1942. Bacterial reduction of tetrathionate. Nature, Lond., 150, 94.

SMITH, H. G. 1959. On the nature of the selective action of selenite broth. J. Gen. Microbiol., 21, 61 . 